\title{
Anarquismo, poder, classe e transformação social
}

\section{Anarchism, power, class and social change}

\author{
Felipe Corrêa Pedro \\ Mestre em Mudança Social e Participação Política pela Universidade de São Paulo (USP) \\ Editor da Faísca Publicações e do Instituto de Teoria e História Anarquista (ITHA) \\ felipecorreapedro@gmail.com
}

\begin{abstract}
Resumo: O presente artigo discute, por meio de elementos teóricos e históricos, a relação do anarquismo com poder, classe e transformação social. Partindo de uma definição do anarquismo, sustenta que relacionar anarquismo e poder exige superar uma problemática semântica, e propõe conceituar o poder em termos de relação entre forças sociais assimétricas. Sustenta ainda que os anarquistas têm uma concepção e um projeto geral de poder que subsidia sua concepção de classe, estabelecida por meio de um tipo de poder (a dominação), e constitui as bases de sua noção de transformação social, que se caracteriza por: sua crença na capacidade de realização dos sujeitos que constituem parte das distintas classes dominadas, seu investimento na transformação dessa capacidade em força social, seu intento para que esta força aumente permanentemente, sua defesa de um processo revolucionário que permita superar as forças inimigas e substituir o poder dominador da sociedade por um poder autogestionário.
\end{abstract}

Palavras chave: Anarquismo. Poder. Dominação. Classes sociais. Transformação social.

\begin{abstract}
This article discusses, through theoretical and historical elements, the relationship of anarchism with power, class and social change. Starting from a definition of anarchism, it sustains that relate anarchism and power requires overcoming a semantics problematic, and proposes to conceptualize power in terms of asymmetric relationship between social forces. It also sustains that anarchists have a conception and a general project of power that subsidizes their conception of class, established through a kind of power (domination), and constitutes the basis of their notion of social change, which is characterized by: the belief in the capacity of realization of the subjects that form part of the distinct dominated classes, the investment in transforming this capacity into social force, the intent to increase this force permanently, the defense of a revolutionary process that allows to overcome the enemy forces and replace the dominating power of society by a self-managed power.
\end{abstract}

Keywords: Anarchism. Power. Domination. Social classes. Social change.

Originais recebidos em: 11/12/2012

Aceito para publicação em: 14/03/2013

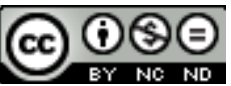
Comercial-Vedada a criação de obras derivadas 3.0 Unported License. 


\section{Anarquismo: teoria e ideologia, princípios e estratégias}

Abordar o anarquismo num estudo como este, implica retomar três posições desenvolvidas mais amplamente em outro trabalho. (Corrêa, 2012)

Primeiramente, sustenta-se que o anarquismo constitui uma ideologia, sendo esta definida como um "conjunto de pensamento e ação fundamentado em preceitos éticos que orienta comportamentos políticos coletivos, pautados em estratégias determinadas. Similar à doutrina política, possui relações com a teoria, mas não se resume a ela." (Corrêa, 2012, p. 80) A ideologia distingue-se da teoria, no sentido de que a segunda está relacionada ao conhecimento da sociedade e a primeira às intervenções que se realizam sobre ela; portanto, o anarquismo se caracteriza mais por seus elementos ideológico-doutrinários do que por questões teórico-metodológicas.

Essa distinção é substantiva, pois assume que a unidade e a coerência histórica do anarquismo está relacionada a seus princípios político-ideológicos e não os métodos de análise e as teorias sociais que têm sido utilizados pelos anarquistas para a interpretação da realidade; conforme se sustenta, no campo teórico, os anarquistas têm utilizado diferentes ferramentas, profundamente conectadas com o tempo e o espaço em que foram e são produzidas.

Em segundo lugar, define-se o anarquismo da seguinte maneira:

O anarquismo é uma ideologia socialista e revolucionária que se fundamenta em princípios determinados, cujas bases se definem a partir de uma crítica da dominação e de uma defesa da autogestão; em termos estruturais, o anarquismo defende uma transformação social fundamentada em estratégias, que devem permitir a substituição de um sistema de dominação por um sistema de autogestão. (Corrêa, 2012, p. 87)

Discutindo-se a definição de maneira mais pormenorizada, argumenta-se que há um conjunto relativamente fixo de dez princípios político-ideológicos que se mantém, contínua e permanentemente, entre os anarquistas, e que constituem as bases fundamentais dessa definição de anarquismo. Tais princípios são:

1.) Ética e valores. A defesa de uma concepção ética, capaz de subsidiar críticas e proposições racionais, pautada nos seguintes valores: liberdade individual e coletiva; igualdade em termos econômicos, políticos e sociais; solidariedade e apoio mútuo; estímulo permanente à felicidade, à motivação e à vontade. 2.) Crítica da dominação. A crítica das dominações da classe constituídas por exploração, coação física e dominações político-burocrática e cultural-ideológica - e de outros tipos de dominação (gênero, raça, imperialismo, etc.). 3.) Transformação social do sistema e do modelo de poder. O reconhecimento de que as estruturas sistêmicas fundamentadas em distintas dominações constituem sistemas de dominação e a identificação, por meio de uma crítica racional, fundamentada nos valores éticos especificados, de que esse sistema tem de ser transformado em um sistema de autogestão. Para isso, torna-se fundamental a transformação do modelo de poder vigente, 
de um poder dominador, em um poder autogestionário. Nas sociedades contemporâneas, essa crítica da dominação implica uma oposição clara ao capitalismo, ao Estado e às outras instituições criadas e sustentadas para a manutenção da dominação. 4.) Classes e luta de classes. A identificação de que, nos diversos sistemas de dominação, com suas respectivas estruturas de classes, as dominações de classe permitem conceber a divisão fundamental da sociedade em duas grandes categorias globais e universais, constituídas por classes com interesses inconciliáveis: as classes dominantes e as classes dominadas. O conflito social entre essas classes caracteriza a luta de classes. [...] Outras dominações devem ser combatidas concomitantemente às dominações de classe, sendo que o fim das últimas não significa, obrigatoriamente, o fim das primeiras. 5.) Classismo e força social. A compreensão de que essa transformação social de base classista implica uma prática política, constituída a partir da intervenção na correlação de forças que constitui as bases das relações de poder vigentes. Busca-se, nesse sentido, transformar a capacidade de realização dos agentes sociais que são membros das classes dominadas em força social, aplicando-a na luta de classes e buscando aumentá-la permanentemente. [...] 6.) Internacionalismo. A defesa de um classismo que não se restrinja às fronteiras nacionais e que, por isso, fundamente-se no internacionalismo, o qual implica, no caso das práticas junto a agentes dominados por relações imperialistas, a rejeição do nacionalismo e, nas lutas pela transformação social, a necessidade de ampliação da mobilização das classes dominadas para além das fronteiras nacionais. [...] 7.) Estratégia. A concepção racional, para esse projeto de transformação social, de estratégias adequadas, que implicam leituras da realidade e o estabelecimento de caminhos para as lutas. [...] 8.) Elementos estratégicos. Ainda que os anarquistas defendam estratégias distintas, alguns elementos estratégicos são considerados princípios: o estímulo à criação de sujeitos revolucionários, mobilizados entre os agentes que constituem parte das classes sociais concretas de cada época e localidade, as quais dão corpo às classes dominadas, a partir de processos que envolvem a consciência de classe e do estímulo à vontade de transformação; o estímulo permanente ao aumento de força social das classes dominadas, de maneira a permitir um processo revolucionário de transformação social; a coerência entre objetivos, estratégias e táticas e, por isso, a coerência entre fins e meios e a construção, nas práticas de hoje, da sociedade que se quer amanhã; a utilização de meios autogestionários de luta que não impliquem a dominação, seja entre os próprios anarquistas ou na relação dos anarquistas com outros agentes; a defesa da independência e da autonomia de classe, que implica a recusa às relações de dominação estabelecidas com partidos políticos, Estado ou outras instituições ou agentes, garantindo o protagonismo popular das classes dominadas, o qual deve ser promovido por meio da construção da luta pela base, de baixo para cima, envolvendo a ação direta. 9.) Revolução social e violência. A busca de uma revolução social, que transforme o sistema e o modelo de poder vigentes, sendo que a violência, como expressão de um nível mais acirrado de confronto, é aceita, na maioria dos casos, por ser considerada inevitável. Essa revolução implica lutas combativas e mudanças de fundo nas três esferas estruturadas da sociedade e não se encontra dentro dos marcos do sistema de dominação presente - está além do capitalismo, do Estado, das instituições dominadoras. 10.) Defesa da autogestão. A defesa da autogestão que fundamenta a prática política e a estratégia anarquistas constitui as bases para a sociedade futura que se deseja construir e envolve socialização da propriedade em termos econômicos, o autogoverno democrático em termos políticos e uma cultura autogestionária. [...]. (Corrêa, 2012, p. 143-147)

Em terceiro, argumenta-se que o anarquismo possui debates internos relevantes, que fornecem as bases para o estabelecimento de suas correntes. As diferentes posições teóricas não constituem fundamentos para a definição das correntes anarquistas, visto 
que não servem sequer para definir o próprio anarquismo. Nas criticas dos anarquistas à dominação, não há debates relevantes. Em sua defesa da autogestão, há quatro debates fundamentais: mercado autogestionário versus planificação democrática, coletivismo versus comunismo, articulação política pelo local de moradia ou de trabalho, limites e possibilidades da cultura; ainda assim, afirma-se que esses debates são secundários em relação aos debates estratégicos.

Dentre as diferentes estratégias dos anarquistas, apresentam-se quatro debates, que são os mais relevantes, por razão de sua continuidade e permanência histórica, assim como pela maior falta de acordo entre os anarquistas: posições favoráveis e contrárias à organização, sendo que entre os organizacionistas, há distintas concepções de organização no nível de massas, incluindo articulação comunitária e sindical, e diferentes concepções que sobre a organização específica anarquista; posições favoráveis e contrárias aos ganhos de curto prazo (reformas), tomando em conta sua contribuição ou não para a revolução; posições distintas em relação ao contexto de utilização e a função da violência, considerando se ela deve responder a movimentos de massas já estabelecidos ou se ela pode funcionar como um "gatilho" gerador desses movimentos; posições diferentes em relação ao modelo da organização específica anarquista, um debate transversal aos outros.

A definição das correntes anarquistas é estabelecida em função dos três primeiros debates estratégicos. O anarquismo de massas, historicamente, defende a organização em distintos níveis, sustenta que, dependendo da maneira como forem conquistadas, as reformas podem conduzir à revolução, e afirma que a violência deve fortalecer movimentos já estabelecidos; as duas estratégias mais conhecidas dessa corrente são o sindicalismo revolucionário e o anarco-sindicalismo. O anarquismo insurrecionalista, historicamente, se opõe à organização estruturada, contrapõe-se às lutas por reformas e considera que a violência deve funcionar como um gatilho para gerar movimentos revolucionários.

$\mathrm{O}$ argumento fundamental deste artigo é que a mesma coerência do anarquismo, que se pode verificar em seus princípios político-ideológicos, existe na posição dos anarquistas acerca dos temas poder, classe e transformação social; entretanto, para que isso possa ser demonstrado, é fundamental extrapolar a problemática semântica que envolve os termos em questão e analisar o conteúdo histórico das posições anarquistas. 


\section{Anarquismo e poder}

A discussão do poder no anarquismo tem sido prejudicada pelos problemas semânticos, que - conforme afirma Tomás Ibáñez, em seu rigoroso estudo sobre o tema, que leva em conta mais de 300 obras - não se restringem aos estudos anarquistas:

O fato de os pesquisadores das relações de poder seguirem, depois de tantos anos, dedicando parte importante de seus esforços para esclarecer e depurar o conteúdo da noção de poder, o fato de não haver um acordo minimamente generalizado sobre o significado desse termo e o fato de as polêmicas se darem mais sobre as diferenças de conceituação do que sobre as operações e resultados conseguidos a partir dessas conceituações, tudo isso indica claramente que a teorização sobre o poder encontra-se, em algum momento, com um obstáculo epistemológico que a impede de progredir. (Ibáñez, 1982, p. 11)

A falta de significação comum em relação ao termo poder e o obstáculo epistemológico aos quais se refere Ibáñez faz-se notar, também, entre os próprios anarquistas clássicos, complicando a realização de uma discussão qualificada do poder no anarquismo. Bakunin (1998, p. 100) enfatiza que "quem fala de poder político, fala de dominação"; Kropotkin (1970a, p. 189) afirma que "na medida em que os socialistas constituírem um poder na sociedade burguesa e no Estado atual, seu socialismo morrerá"; Malatesta $(2008$, p. 183; 200) critica os socialistas autoritários afirmando que eles "se propõem à conquista do poder" para emancipar o povo, que isso significa utilizar o "mesmo mecanismo que hoje o tem escravizado" e, como proposta libertária, sugere a "abolição do governo e de todo poder".

Para os anarquistas clássicos, o termo poder está, em praticamente todos os casos, associado ao Estado e/ou à dominação. Além disso, eles tratam, muitas vezes, como sinônimos os termos poder, dominação e autoridade. ${ }^{1}$ Entretanto, o poder deve ser conceituado tão-somente como dominação ou Estado? Poder, dominação e autoridade são sinônimos? Sustenta-se que não, em ambos os casos.

Pode-se dizer que a posição hegemônica no anarquismo, até os anos 1970, e que ainda existe na atualidade, é a de que os anarquistas são contrários ao poder, compreendendo-o como sinônimo de dominação e/ou de Estado. Posições como a de Patrick Rossineri (2011, p. 19-20) foram, e ainda são, relativamente comuns: "toda a

\footnotetext{
${ }^{1}$ Essa problemática semântica também pode ser vista nas traduções, como no caso de Estatismo $e$ Anarquia, de Bakunin. A tradução em castelhano coloca: "Não se deve dar nem a eles e nem a ninguém o poder, porque aquele que está investido de um poder tornar-se-á, inevitavelmente, pela lei social imutável, um opressor, um explorador da sociedade". (grifos meus) (Bakunin, 2006, p. 159-160) A tradução em português coloca: "Não há por que lhes dar, assim como nenhum outro, autoridade, pois quem dela é investido, torna-se, de modo infalível, segundo uma lei social invariável, um opressor e explorador da sociedade". (grifei) (Bakunin, 2003, p. 166) Poder e autoridade são utilizados como tradução do mesmo termo original.
}

Em Debat: Rev. Dig., ISSNe 1980-3532, Florianópolis, n. 8, p. 69-89, jul-dez, 2012. 
teoria anarquista se funda sobre uma crítica ao poder e aos efeitos que ele produz". E ainda: "Os anarquistas nunca propuseram o poder popular, nem o poder para uma classe. [...] Quando existe simetria e reciprocidade em uma relação social, é porque a relação de poder deixou de existir." Tais posições, extraídas de uma análise em grande medida supérflua e semântica, foram responsáveis, em alguns momentos históricos, pelo afastamento de anarquistas da política, da intervenção real no jogo de forças da sociedade, terminando por resigná-los ao papel de observadores críticos da realidade, sem condições de nela intervir.

Entretanto, aprofundando a análise e extrapolando os aspectos semânticos, podese afirmar, como se vem fazendo mais enfática e claramente nos últimos 40 anos, que não parece aceitável, conforme coloca Ibáñez (2007, p. 42), “considerar que a relação do pensamento libertário com o conceito de poder só possa ser formulada em termos de negação, de exclusão, de rechaço, de oposição e até de antinomia". Ibáñez (2007, pp. 42-44) considera, ainda, que as inúmeras definições do poder podem ser agrupadas em três grandes abordagens: 1.) do poder como capacidade, 2.) do poder como assimetria nas relações de força, e 3.) do poder como estruturas e mecanismos de regulação e controle. Tomando em conta essas três abordagens, Ibáñez afirma: "existe uma concepção libertária do poder, e é falso que esta tenha que constituir uma negação do poder".

Exemplos históricos são abundantes para demonstrar que os anarquistas nunca se opuseram à noção de que pessoas, grupos e classes sociais possuem capacidade de realizar algo; que a sociedade é composta por diversas forças em jogo e que, se buscam uma transformação social, os anarquistas devem estimular o crescimento de uma força determinada que se sobreponha às forças inimigas, então preponderantes no campo social; que, ao mesmo tempo em que se opõem às estruturas e mecanismo de regulação e controle autoritárias, os anarquistas propõem outras, de base libertária, que constituem os fundamentos da sociedade futura que propõem.

Bakunin (2009, p. 34) afirma que "o ser humano mais ínfimo representa uma minúscula fração da força social”. Kropotkin (1970b, p. 69) enfatiza: força - e uma grande quantidade de força - é necessária para prevenir os trabalhadores de se apropriar daquilo que consideram ter sido injustamente apropriado por poucos. Malatesta recomenda: 
necessária para vencer; devemos propagar nosso ideal e preparar as forças morais e materiais necessárias para vencer as forças inimigas e organizar a nova sociedade." (Malatesta, 2008, p. 94)

Vencer as forçar inimigas implica, para Malatesta, fazer a revolução, socializando a economia e a política com a "criação de novas instituições, de novos agrupamentos, de novas relações sociais"; trata-se de iniciar uma reconstrução social que possa "prover a satisfação das necessidades imediatas e preparar o porvir", que deverá destruir "os privilégios e as instituições nocivas e fazendo [...] funcionar, em benefício de todos, as instituições úteis que hoje servem exclusiva ou principalmente para benefício das classes dominantes”. (Richards, 2007, pp. 147; 154)

Não há, portanto, como afirmar, a partir da tripla definição de Ibáñez, que os anarquistas sejam contrários ao poder.

\section{Poder: entre a dominação e a autogestão}

Quando os anarquistas afirmaram ser contra o "poder”, coloca Ibáñez (2007, p. 45), eles utilizavam o "termo 'poder' para se referir, de fato, a um 'certo tipo de relação de poder', ou seja, muito concretamente, ao tipo de poder que se encontra nas 'relações de dominação', nas 'estruturas de dominação', nos 'dispositivos de dominação', ou nos ‘instrumentos de dominação' etc.” A crítica anarquista à exploração, à coerção, à alienação, sempre teve como pano de fundo uma crítica à dominação de maneira geral, incluindo a dominação de classe e as dominações de gênero, raça e entre países ou povos (imperialismo).

Ao defender o federalismo, os anarquistas sustentavam, segundo René Berthier (2011, p. 32), relações sociais forjadas por uma ampla participação nos processos decisórios, por meio de um sistema em que não houvesse "nem captação de todo o poder pelo cume (centralismo), nem atomização do poder (autonomismo)". Conforme aponta Frank Mintz (1977, p. 26-27), o termo "autogestão" surgiu somente nos anos 1960 para referir-se, também, a um modelo organizativo respaldado em uma ampla participação popular. ${ }^{2}$ Ainda que tenham havido tentativas posteriores de restringir o

\footnotetext{
${ }^{2}$ Realizando um levantamento em dicionários da época, Mintz verificou que, durante a década de 1950, o termo ainda não aparecia em idiomas hispânicos; nos idiomas eslavos, o termo "samupravlenie", que era traduzido como "governo ou poder independente", "auto-administração" e "autonomia", só foi traduzido como autogestão a partir da década de 1960. Ele afirma ainda que: "[...] do ponto de vista político, utilizou-se 'gestão direta' e logo se adotou 'autogestão'. Assim, a revista Noir et Rouge publicou um estudo em duas partes sobre as coletividades espanholas cujo número de junho de 1965 intitulava-se 'Coletividades Espanholas' e, o número seguinte, de fevereiro de 1966, 'Autogestão'. Também as descrições da Iugoslávia e da Argélia popularizaram a palavra.” (Mintz, 1977, p. 26-27)
}

Em Debat: Rev. Dig., ISSNe 1980-3532, Florianópolis, n. 8, p. 69-89, jul-dez, 2012. 
federalismo ao âmbito político e a autogestão ao econômico, o fato é que os termos envolvem noções bastante próximas e têm sido comumente utilizados pelos anarquistas. A defesa anarquista da socialização da propriedade privada, da socialização do poder político, de uma cultura que reforce esse projeto, e de uma articulação de baixo para cima, fundamenta-se em uma defesa da autogestão generalizada, tomada em conta em todos seus aspectos sociais, e que contém a noção de federalismo.

Dominação e autogestão estão diretamente relacionadas ao conceito de poder que será aqui definido de acordo com a segunda abordagem de Ibáñez, como assimetria nas relações de força. Definir o poder dessa maneira permite conceituá-lo, mais especificamente, como uma relação que se estabelece nas lutas e disputas entre diversas forças sociais, quando uma(s) força se impõe à(s) outra(s); poder e relação de poder funcionam, dessa maneira, como sinônimos. (Corrêa, 2011a) O vínculo entre a dominação, a autogestão e o poder se dão por meio da noção de participação; considerando que a participação é estabelecida pelas relações de poder, ela pode ser maior, aproximando-se da noção de autogestão, ou menor, aproximando-se da dominação. Dominação e autogestão seriam, assim, tipos-ideais das relações de poder, tomando por base um eixo da participação; quando mais dominador for o poder, menor participação; quanto mais autogestionário, maior participação.

Os extremos constituídos pela dominação e pela autogestão demarcam,
teoricamente, as possibilidades lógicas de limites nos processos de
participação. Independente da possibilidade real ou não de se chegar a um
dos tipos ideais, esses extremos, o que é relevante é concebê-los como um
modelo teórico lógico para a compreensão das diferentes relações de poder,
dos tipos dessas relações, e das distintas formas de participação que delas
derivam. [...] Conceber as relações de poder dentro desses dois extremos, a
partir do eixo da participação, constitui um método de análise para relações
nos distintos níveis. (Corrêa, 2011a)

De acordo com esse modelo, o objetivo dos anarquistas foi sempre sustentar relações sociais que incorporassem maior participação e substituíssem poder dominador - “dominação, hierarquia, alienação, monopólio das decisões por uma minoria, estrutura de classes e exploração" - por poder autogestionário - "autogestão, participação ampla nas decisões, agentes não alienados, relações não hierárquicas, sem relações de dominação, sem estrutura de classes e exploração". (Corrêa, 2012, p. 98)

Tal maneira de conceber o poder contesta que ele seja sinônimo de dominação e/ou de Estado. A dominação, segundo se sustenta, é um tipo de poder, assim como a autogestão; as relações de poder podem se estabelecer envolvendo maior ou menor participação; assim, poder não implica, necessariamente dominação. O Estado é um 
elemento central do sistema de dominação e, em todas as suas formas históricas, tem implicado relações de dominação, fundamentalmente as de tipo político-burocrático e a coerção; por outro lado, as estruturas de poder político autogestionário, defendidas pelos anarquistas para a substituição do Estado, também envolvem poder, mas não dominação.

\section{Anarquismo e classes sociais}

Michael Schmidt e Lucien van der Walt $(2009$, p. $71 ; 45 ; 51)$ afirmam que o anarquismo é um tipo revolucionário "de socialismo libertário que surgiu na segunda metade do século XIX"; segundo afirmam, "foi do movimento e das associações da classe trabalhadora que o anarquismo nasceu". Assim, pode-se conceber o anarquismo como uma ideologia que surge no seio das classes dominadas durante o processo de luta de classes levado a cabo no século XIX. "Os anarquistas [...] viam a luta de classes como um aspecto necessário da transformação social e viam nas vítimas da dominação e na exploração de classe - o operariado e o campesinato - os agentes dessa mudança". O anarquismo, uma ideologia essencialmente classista, possui críticas enfáticas à dominação de classe e projetos concretos de classe, que buscam substituir o sistema de dominação e sua estrutura de classes por um sistema de autogestão, em que as classes sociais, e a própria estrutura de dominadores e dominados, deixaria de existir.

Para os anarquistas, em geral, as classes sociais são estabelecidas a partir da noção de dominação, e estão, portanto, para além da propriedade dos meios de produção e da exploração econômica do trabalho. Ainda que reflexões contemporâneas como as de Alfredo Errandonea (1989) aprofundem e recontextualizem o debate, pode-se afirmar que, desde os primeiros tempos, os anarquistas constataram a dominação nas esferas econômica, política/jurídica/militar, cultural/ideológica e, portanto, os sistemas que envolvem o capitalismo e o Estado, e perceberam seu impacto sobre a questão das classes sociais.

Ao refletir sobre as classes sociais de seu tempo, Bakunin enfatiza que a diferença entre elas é bastante clara; a aristocracia nobiliária, a aristocracia financeira, a alta burguesia, a pequena burguesia, os proletários das fábricas e das cidades, os grandes proprietários de terra, os rendeiros, os camponeses, os fazendeiros, os proletários do campo seriam classes sociais concretas de seu tempo. Ele sustenta ainda que 
naturais uma da outra: as classes politicas, compostas por todos os privilegiados, tanto da terra quanto do capital, ou mesmo somente da educação burguesa, e as classes operárias, deserdadas tanto do capital quanto da terra, e privadas de qualquer educação e de qualquer instrução. (Bakunin, 1988, p. 16)

Kropotkin (2005, p. 180) afirma que, em sua crítica do Estado, os anarquistas têm demonstrado que "a missão de todos os governos, monárquicos, constitucionais e republicanos, é proteger e manter pela força os privilégios das classes dominantes, aristocracia, padralhada e burguesia". Posições similares às defendidas por Malatesta, quando aponta os resultados das lutas humanas que terminaram por dividir a sociedade em oprimidos e opressores.

Disto depende o estado de miséria em que se encontram geralmente os trabalhadores, e todos os males decorrentes: ignorância, crime, prostituição, definhamento físico, abjeção moral, morte prematura. Daí a constituição de uma classe especial (o governo) que, provida dos meios materiais de repressão, tem por missão legalizar e defender os proprietários contra as reivindicações do proletariado. Ele se serve, em seguida, da força que possui para arrogar-se privilégios e submeter, se ela pode fazê-lo, à sua própria supremacia, a classe dos proprietários. Disso decorre a formação de outra classe especial (o clero), que por uma série de fábulas relativas à vontade de Deus, à vida futura, etc, procura conduzir os oprimidos a suportarem docilmente o opressor, o governo, os interesses dos proprietários e os seus próprios. (Malatesta, 2000, p. 9)

Bakunin, Kropotkin e Malatesta, ao definir os fundamentos das classes sociais, têm como base as dominações que se dão nas três esferas sociais. Enfatizam distintos tipos de dominação que possuem impacto na definição das classes sociais: a exploração do trabalho de proletários urbanos, rurais e do campesinato, fruto da dominação econômica; a coação física e a dominação político-burocrática, fruto da dominação política/jurídica/militar; a educação e a religião, que envolvem a alienação, a obediência, fortalecendo os interesses dominantes, fruto da dominação cultural/ideológica.

Schmidt e van der Walt enfatizam que "a ampla tradição anarquista vê as classes estabelecidas pelo controle de um conjunto de recursos e não somente da propriedade econômica". A definição das classes sociais no anarquismo, segundo afirmam,

não diz respeito apenas às relações de produção, mas também às relações de dominação, não apenas à propriedade dos meios de produção, mas também à propriedade dos meios de coerção - a capacidade de forçar fisicamente as decisões - e dos meios de administração - os instrumentos que governam a sociedade. Vista desta maneira, a propriedade desigual dos meios de produção constitui uma descrição necessária, mas não suficiente de um sistema de classes." (Schmidt; van der Walt, 2009, p. 109)

Essa definição das classes sociais com base na dominação teve, historicamente, uma implicação direta sobre a estratificação social e a noção de sujeito revolucionário 
dos anarquistas. Ao passo que as classes dominadas incluíram trabalhadores assalariados, precarizados, marginalizados e campesinato, as classes dominantes incluíram, além dos proprietários dos meios de produção, “presidentes, reis, generais, membros do parlamento, prefeitos, diretores dos departamentos do governo, dirigentes de empresas estatais", entre outros. (Schmidt; van der Walt, 2009, p. 110)

No processo de luta de classes, os anarquistas impulsionaram movimentos populares opondo-se diretamente a proprietários, governantes, militares de alta patente, policiais, juízes, clero e outros inimigos de classe. Buscaram fortalecer distintos sujeitos oprimidos; conforme apontam Schmidt e van der Walt, além do campesinato, foram também mobilizados outros setores de trabalhadores urbanos.

Primeiro, trabalhadores temporários ou por período, como trabalhadores da
construção, das docas, rurais, marinheiros, da indústria do gás, cujas vidas
caracterizaram-se pela instabilidade, pelas freqüentes mudanças de emprego e
pelo movimento em busca de trabalho; e segundo, trabalhadores da indústria
leve e pesada, como trabalhadores de fábricas, mineiros e ferroviários. Além
dessas categorias principais, houve também um número menor de
trabalhadores e profissionais qualificados, particularmente jornalistas,
professores, enfermeiras e médicos. [...] (Schmidt; van der Walt, 2009, p.
279)

Os sujeitos revolucionários historicamente envolvidos nas mobilizações impulsionadas pelos anarquistas não estavam somente em meio ao proletariado urbanoindustrial, ainda que este tenha sido um setor importante - talvez o mais relevante, em termos quantitativos - nessas mobilizações. Os anarquistas envolveram-se em movimentos populares cuja base assentava-se tanto em trabalhadores da cidade quanto do campo, tanto em assalariados quanto camponeses, assim como em precarizados, marginalizados e pobres em geral.

\section{Anarquismo e transformação social}

A estratégia revolucionária do anarquismo vem se fundamentando em um modelo de conflito social para a superação do sistema de dominação e o estabelecimento do sistema de autogestão. Trata-se, assim, de substituir o capitalismo, o Estado e a dominação de maneira geral, pela propriedade e o poder socializados e por novas relações sociais libertárias.

O processo para esta transformação social preconizado historicamente pelos anarquistas fundamenta-se em cinco aspectos: 1.) a definição das classes sociais e do processo de luta de classes; 2.) a crença na capacidade de realização das classes dominadas; 3.) a articulação e a mobilização dessas classes, o estímulo permanente à 
conformação e ao crescimento de sua força social e a busca de superação dos inimigos estratégicos; 4.) a escolha de meios adequados para esse processo; 5.) o estabelecimento de um poder autogestionário, com suas respectivas estruturas de regulação e controle.

Anteriormente, apontou-se como três clássicos anarquistas - Bakunin, Kropotkin e Malatesta - compreendem algumas dessas questões. Demonstrou-se: sua concepção das classes sociais a partir do conceito de dominação e sua definição da luta de classes entre dominadores e dominados, opressores e oprimidos; sua crença na capacidade de realização das classes dominadas e dos oprimidos em geral; sua busca de uma nova sociedade, socialista e libertária, conformada sobre novas instituições e relações sociais.

Para a compreensão do processo de articulação e mobilização das classes dominadas e do estímulo ao crescimento de sua força social, torna-se fundamental discutir o conceito de força social e diferenciá-lo de capacidade de realização.

A noção de força social - desenvolvida por Proudhon (s/d, p. 211-229) em sua dialética serial, e que foi, em certa medida, apropriada por Bakunin $(2009$, p. 35) implica uma compreensão de que, nos conflitos sociais e na luta de classes, as classes dominadas devem se articular, pois quando os indivíduos se associam, "conjugam seus esforços para alcançar um objetivo comum, constitui-se entre eles uma nova força que ultrapassa, e de longe, a simples soma aritmética dos esforços individuais de cada um". Articular e mobilizar as classes dominadas possibilitaria um ganho significativo de força, a qual, levada a cabo coletivamente, teria um resultado muito maior do que a simples soma das forças individuais de cada pessoa envolvida nesse processo. Além disso, a articulação e a organização para intervir nos conflitos e lutas permite transformar a capacidade de realização das classes dominadas em força social, conforme aponta Bakunin:

É verdade, há no povo bastante força espontânea; esta é incomparavelmente
maior que a força do governo, incluindo aquela das classes; todavia, por falta
de organização, a força espontânea não é uma força real. Ela não está em
condição de sustentar uma longa luta contra forças muito mais fracas mas
bem organizadas. Sobre essa incontestável superioridade da força organizada
sobre a força elementar do povo, repousa todo o poder do Estado. Eis por que
a primeira condição da vitória do povo é a união ou a organização das forças
populares. (Bakunin, 2009, p. 67)

Quando fala que uma força espontânea não é uma força real, Bakunin distingue a capacidade de realização dos oprimidos, que se localiza no campo potencial, e sua força social, que permite que as classes dominadas ingressem, de fato, no campo político, como um ator relevante no jogo de forças que forja as relações de poder da 
sociedade. Entretanto, não se trata somente de criar uma força social, mas de permitir que ela consiga enfrentar as classes dominantes e sobrepor suas forças.

Para Kropotkin (1970a, pp. 181-182), esse momento em que as forças populares se sobrepõem às forças capitalistas e estatistas caracteriza-se como uma revolução social. Esta, além das transformações culturais e ideológicas, envolve mudanças substantivas no campo econômico e político: "as duas mudanças, políticas e econômicas, devem caminhar lado a lado, de mãos dadas". Ele afirma que "cada passo em direção à liberdade econômica, cada vitória estabelecida sobre o capitalismo será, ao mesmo tempo, um passo rumo à liberdade política"; ao mesmo tempo, "cada passo no sentido de retirar do Estado cada um de seus poderes e atributos ajudará as massas a estabelecerem sua vitória sobre o capitalismo".

Malatesta, ao refletir sobre a escolha de meios para esse processo, enfatiza a necessidade de uma coerência estratégica entre os fins que se busca atingir e os meios que são empregados para tanto:

\begin{abstract}
Esses meios não são arbitrários: derivam necessariamente dos fins a que nos propomos e das circunstâncias nas quais lutamos. Enganando-nos na escolha dos meios, não alcançamos o objetivo contemplado, mas, ao contrário, afastamo-nos dele rumo a realidades freqüentes opostas, e que são a conseqüência natural e necessária aos métodos que empregamos. Quem se opõe a caminho e se engana de estrada, não vai aonde quer, mas aonde o conduz o caminho tomado." (Malatesta, 2000, p. 11)
\end{abstract}

As posições de Bakunin, Kropotkin e Malatesta implicam noções fundamentais sobre a perspectiva anarquista da transformação social. Bakunin reforça a idéia de Proudhon de que a associação coletiva multiplica as forças individuais e diferencia a capacidade de realização de força social; trata-se, portanto, de articular e mobilizar as classes dominadas e de estimular o crescimento permanente de sua força social. Kropotkin demonstra como um processo revolucionário de transformação deve modificar as relações nas três esferas sociais, sobrepujando as forças inimigas. Malatesta afirma a necessidade de que os meios convirjam com os fins.

Os argumentos de Malatesta proporcionam condições de avançar; fundamentados nos próprios teóricos da estratégia, eles exigem uma coerência entre a realização da tática em relação à estratégia, e entre a realização da estratégia e os objetivos estratégicos. Se os fins da transformação social anarquista se caracterizam por uma mudança no modelo do poder da sociedade - superando um poder dominador e estabelecendo um poder autogestionário -, os meios empregados para tanto devem reforçar a autogestão. 
Meios que não condigam com esse fim devem ser descartados: aqueles que reforçam o capitalismo, o Estado e as instituições que os sustentam; aqueles que retiram das massas o necessário protagonismo no processo de transformação social; aqueles que nelas estimulam o espírito de subserviência e obediência. Construir a autogestão generalizada implica, portanto, a defesa da socialização econômica e política e a transformação revolucionária das instituições sociais, o protagonismo das massas por meio da independência de classe e a construção democrática das lutas pela base.

As posições anarquistas sobre a natureza do Estado e sua concepção das classes sociais constituem um exemplo relevante de aplicação dessa noção de coerência estratégica; elas estão nas bases da cisão entre o anarquismo e a maior parte das correntes marxistas e têm como pano de fundo suas diferentes estratégias de transformação social.

Errandonea (1989, p. 45) afirma que "desde suas origens, o anarquismo foi um movimento sócio-político revolucionário que, em conseqüência com sua postulação antiestatista e antiautoritária, desdenhou do caminho da conquista do poder social centralizado, em benefício da coletivização autogestionária do poder descentralizado". Para os anarquistas, o Estado é uma instituição fundamental do sistema de dominação contemporâneo e um instrumento essencialmente dominador; governantes, militares de alta patente, policiais, juízes são inimigos de classe. A estratégia de tomada do Estado, seja por meio de reformas - como defendem as correntes social-democratas - ou por meio de revolução - como defendem os bolcheviques em suas distintas versões implica, necessariamente, a utilização de um meio que não condiz com fins como a abolição do capitalismo, do Estado, das classes sociais, o socialismo/comunismo, etc. Segundo os anarquistas, conquistar o Estado implica, necessariamente, substituir uma classe dominante por outra, mesmo que os novos governantes tenham origem nas classes dominadas; trata-se de substituir alguns dominadores por outros.

Esse procedimento poderia proporcionar uma mudança social, mas o modelo de poder continuaria a ser caracterizado, essencialmente, pela dominação, pela completa falta de participação. A defesa da transformação no modelo de poder realizada pelos anarquistas implica, obrigatoriamente, o fim do Estado e sua substituição por mecanismos autogestionários de poder que envolvam altos níveis de participação, juntamente com o fim do capitalismo, das instituições e das relações que fundamentam o presente sistema de dominação. 


\section{Poder, classe e transformação social em perspectiva histórica}

Dentre os episódios que mais se destacam na história do anarquismo estão: a Revolta da Macedônia, de 1903; a Revolução Mexicana, iniciada em 1910; a Revolução Russa e Ucraniana, respectivamente de 1917 e 1919; a mobilização na Bulgária entre os anos 1920 e 1940; a Revolução Espanhola, entre 1936 e 1939; a Revolução da Manchúria, na Coréia, entre 1929 e 1932; a mobilização no Uruguai nos anos 1960 e 1970. ${ }^{3}$ Neste momento, sustentam-se argumentos teóricos apresentados anteriormente recorrendo a um ou mais desses episódios históricos.

O pressuposto anarquista nessas e em outras mobilizações se estabelece por meio da crença em uma capacidade de realização das classes dominadas, que pudesse converter-se em força social. No México, o manifesto do Partido Liberal Mexicano (PLM) - o qual, durante a revolução, tornou-se anarquista - "previa uma transformação radical nas relações trabalhistas, na distribuição das terras e na organização da sociedade mexicana"; transformação esta que deveria ser protagonizada pelos pobres. (Samis, 2003, p. 17) Na Ucrânia, segundo a concepção dos makhnovistas: "as massas são capazes", se "entusiasmadas com um verdadeiro ímpeto revolucionário" e se lhes for "deixada a liberdade total de atuar". (Volin, 1976, p. 20) Na Espanha, o ideal de emancipação dos trabalhadores "não se trata de abstrações filosóficas, mas de justiça social, de trabalho solidariamente organizado, de fraternidade ativa criada pelo gozo igualitário dos bens produzidos pelo trabalho de todos". (Leval, 1972, p. 35)

Essa força social deveria ter base classista e, portanto, mobilizar as diferentes classes sociais concretas, que constituem partes do conjunto mais amplo de classes dominadas. " $\mathrm{Na}$ Macedônia, os anarquistas conquistaram um apoio massivo dos camponeses." (Schmidt; van der Walt, 2009, p. 284) Na Ucrânia, o processo revolucionário foi "produzido pura e unicamente pelas camadas mais 'baixas' das massas populares" (Volin, 1976, p. 7); o objetivo dos anarquista era "auxiliar as massas a interpretar a significação da luta que as espera, [...] definir as obras a realizar e os seus objetivos, a tomar as necessárias disposições de combate e organizar as suas forças."

\footnotetext{
${ }^{3}$ Para uma breve história do anarquismo e diversas indicações bibliográficas, ver: Corrêa, 2013. Sobre a Revolta da Macedônia e o anarquismo na Bulgária, ver: Schmidt, 2009; Balkansky, 1982. Sobre a Revolução Mexicana, ver: Zarcone, 2006; Trejo, 2005. Sobre a Revolução Russa, ver: Tragtenberg, 2007; Skirda, 2000. Sobre a Revolução Ucraniana, ver: Schujman, 2000; Aschinov, 1976. Sobre a Revolução Espanhola, ver: Paz, s/d; Peirats, 2006; Leval, 1972. Sobre a Revolução na Manchúria e o anarquismo na Coréia, ver: Crisi et alli, 2013. Sobre o anarquismo no Uruguai, ver: Mechoso, 2011, 2005, 2006, 2009; Rugai, 2003.
}

Em Debat: Rev. Dig., ISSNe 1980-3532, Florianópolis, n. 8, p. 69-89, jul-dez, 2012. 
(Arshinov, 1976, p. 259) Na Espanha, durante a revolução, "indústrias e propriedades rurais [foram] colocadas sob autogestão de operários e camponeses", um processo no qual "anarquistas e sindicalistas tiveram um papel central". (Schmidt; van der Walt, 2009, p. 180) No Uruguai, a radicalização dos trabalhadores contou, no seio da Convención Nacional de Trabajadores (CNT), impulsionada pelos anarquistas, com "mobilizações do movimento operário organizado na CNT". (Rugai, 2003, p. 220)

$\mathrm{Na}$ busca do crescimento permanente da força social classista, os anarquistas, por meio das organizações que participavam e impulsionavam, tinham por objetivo derrotar as forças inimigas e estabelecer suas proposições. No México, “o PLM rejeitava o nacionalismo mesmo tendo que lutar tanto contra o capitalismo e o imperialismo, recomendando a resistência no México como parte de uma luta de classes global”. (Schmidt; van der Walt, 2009, p. 315) Na Bulgária, os anarquistas tiveram de lutar contra capitalistas e "tanto contra o fascismo, quanto contra o stalinismo"; estabeleceram "um movimento de massas com diversidade e resistência notáveis". (Schmidt, 2009, p. 6)

O movimento anarquista búlgaro edificou-se com uma força formidável, o terceiro maior do campo da esquerda, usando o desencanto dos trabalhadores com o reformismo agrário e comunista para construir muitos sindicatos urbanos, e, depois, inserindo-se em todos os níveis da sociedade, com uma rede de organismos interligados agregando trabalhadores, operários, estudantes e guerrilheiros. (Schmidt, 2009, p. 46)

$\mathrm{Na}$ Manchúria, os anarquistas defendiam a criação de um poder próprio; “é notório que os libertários coreanos estejam falando de um poder próprio das classes oprimidas". (Crisi et alli, 2013, p. 8) No Uruguai, "a organização [FAU] gestou uma concepção de 'poder popular', não estatal, organizado de baixo para cima, mas possuindo organismos de coordenação global”. (Rugai, 2003, p. 205-206)

Nesse processo de superar estabelecer suas próprias forças, e adequando coerente e estrategicamente os fins que buscavam atingir e os meios utilizados para tanto, os anarquistas buscaram impulsionar meios que estimulassem a autogestão e contrariassem a dominação; reivindicaram a independência de classe em relação a partidos, Estados, instituições e agentes que ameaçassem o protagonismo popular, a construção democrática das lutas pela base, por meio da ação direta. Na Rússia, os anarquistas defenderam os sovietes com os seguintes argumentos: "o poder deveria ser descentralizado da seguinte maneira: cada indivíduo se coloca em acordo com outros para formar uma comuna, a federação de comunas forma uma província (região, cidade, distrito, bairro), e da federação das províncias surge uma república federativa pan- 
russa." (Skirda, 2000, p. 82) Na Rússia, buscou-se "a independência verdadeira e completa do movimento, que foi consciente e energicamente garantida contra as forças intrusas". (Volin, 1976, p. 21) No Uruguai, tratava-se de construir a "ação direta em todos os níveis", por meio de "vários âmbitos de atuação", de maneira a "construir o protagonismo da classe através de seus próprios organismos". (Rugai, 2003, p. 165; 256)

Foram várias as ferramentas de luta utilizadas nesse processo. Organizações sindicais, nas cidades e nos campos, incluindo mobilização por local de trabalho e moradia, como foi o caso da Confederación Nacional de Trabajadores (CNT) espanhola; organizações armadas de defesa, como foram os casos do Exército Insurrecional Revolucionário da Ucrânia e da Organização Popular Revolucionária - 33 Orientales (OPR-33), do Uruguai; organizações políticas anarquistas, como foram os casos do PLM no México e da Federação dos Anarco-Comunistas da Bulgária (FAKB); sovietes (conselhos) populares, como os que constituíram as bases da revolução na Rússia; cooperativas, como as Vlassovden, impulsionadas pelos búlgaros.

Nos processos revolucionários que mais avançaram, estabeleceram-se estruturas autogestionárias de regulação e controle. Na Macedônia, os estabelecimentos da Comuna de Krouchevo e da Comuna de Strandzha fundaram as bases de "um movimento revolucionário de libertação social com aspectos claramente libertários" (Balkansky, 1982, p. 5); realizaram experiências de autogestão durante um mês, constituindo a primeira tentativa local de edificar uma nova sociedade sobre os princípios do comunismo libertário. Na Rússia,

os anarco-sindicalistas controlam um certo número de comitês de fábrica, de sindicatos de padeiros, metalúrgicos, doqueiros etc. Eles enalteciam a tomada direta e coletiva pelos próprios trabalhadores de toda a produção. Esse controle operário distingue-se daquele preconizado pelos bolcheviques por razão de sua organização pela base e não pelo Estado. (Skirda, 2000, p. 67)

$\mathrm{Na}$ Espanha, os primeiros organismos estabelecidos pela revolução foram os "Comités de Abastos", de distribuição de alimentos; "desses comitês partiram as primeiras medidas de distribuição e racionamento" (Peirats, 2006, pp. 131-132), que incluíam prioridade para feridos na guerra, crianças e idosos. $\mathrm{Na}$ Manchúria, com o estabelecimento da Comuna de Shimin, a autogestão se estabeleceu em um território com mais de dois milhões de camponeses e "conseguiu libertar grandes zonas rurais e pequenos povoados. Foram instalados, não sem inconvenientes, Conselhos Administrativos que suplantaram e extinguiram em todos os níveis o Estado.” Por meio 
de uma estrutura conselhista, que contava com "Conselhos Municipais ou de Aldeias, [...] Conselhos Distritais [...] e Conselhos de Área ou Regionais", se "promoveram juntas de decisão de democracia direta”. (Crisi et alli, 2013, p. 4; 10)

\section{Apontamentos conclusivos}

Os elementos teóricos e as experiências históricas discutidas, subsidiam as teses desenvolvidas ao longo deste artigo. Os anarquistas têm uma concepção e um projeto geral de poder que subsidia sua concepção de classe, estabelecida por meio de um tipo de poder (a dominação), e constitui as bases de sua noção de transformação social, que se caracteriza por: sua crença na capacidade de realização dos sujeitos que constituem parte das distintas classes dominadas, seu investimento na transformação dessa capacidade em força social, seu intento para que esta força aumente permanentemente, sua defesa de um processo revolucionário que permita superar as forças inimigas e substituir o poder dominador da sociedade por um poder autogestionário.

\section{Bibliografia}

ARSHINOV, Piotr. História do Movimento Macknovista: a insurreição dos camponeses na Ucrânia. Lisboa: Assírio e Alvim, 1976.

BALKANSKY, Gr. Histoire du Movement Libertaire en Bulgarie. Antony: Groupe FresnesAntony (Federation Anarchiste), 1982.

BANCAL, Jean. Proudhon: pluralismo e autogestão. Vol. I. Brasília: Novos Tempos, 1984.

BAKUNIN, Mikhail. Estatismo e Anarquia. São Paulo: Imaginário/Ícone, 2003. . Estatismo y Anarquía. Buenos Aires, Anarres, 2006.

. Deus e o Estado. São Paulo: Imaginário, 2000.

. Federalismo, Socialismo, Antiteologismo. São Paulo: Cortez, 1988.

. A Ciência e a Questão Vital da Revolução. São Paulo: Imaginário/Faísca, 2009. 
. “A Ilusão do Sufrágio Universal”. In: WOODCOCK, George (org.). Os Grandes

Escritos Anarquistas. Porto Alegre: LP\&M, 1998.

BERTHIER, René. Do Federalismo. São Paulo: Imaginário, 2011.

BONOMO, Alex Buzeli. "Introdução". In: BAKUNIN, Mikhail. Deus e o Estado. São Paulo: Hedra, 2011.

CORRÊA, Felipe. "Poder, Dominação e Autogestão". In: Anarkismo.net, 2011a.

[http://www.anarkismo.net/article/21065]

. "Crear um Pueblo Fuerte". In: Anarquismo y Poder Popular: teoría y práctica

suramericana. Bogotá: Gato Negro, 2011 b.

. Rediscutindo o Anarquismo: uma abordagem teórica. São Paulo: USP (Mudança

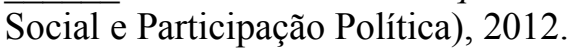

. Surgimento e Breve Perspectiva Histórica do Anarquismo (1868-2012). São Paulo:

Biblioteca Virtual Faísca, 2013.

CRISI, Emílio et alli. Revolución Anarquista en Corea: la Comuna de Shinmin (1929-1932) y otros textos sobre el anarquismo coreano. ITHA, 2013.

EDICIONES GATO NEGRO (org.). Anarquismo y Poder Popular: teoría y práctica suramericana. Bogotá: Gato Negro, 2011.

ERRANDONEA, Alfredo. Sociologia de la Dominación. Montevideu/Buenos Aires:

Nordan/Tupac, 1989.

GUILLAUME, James. L'Internationale: documents et souvenirs. 2 vols. Paris: Gérard Lebovici, 1985.

GURVITCH, Georges. Los Fundadores Franceses de la Sociología Contemporánea: SaintSimon y Proudhon. Buenos Aires: Galatea / Nueva Vision, 1958.

IBÁÑEZ, Tomás. Poder y Libertad. Barcelona: Hora, 1982.

"Por un Poder Político Libertario". In: Actualidad del Anarquismo. Buenos Aires:

Anarres, 2007.

Em Debat: Rev. Dig., ISSNe 1980-3532, Florianópolis, n. 8, p. 69-89, jul-dez, 2012. 
KROPOTKIN, Piotr. "Fatalidade da Revolução". In: O Princípio Anarquista e Outros Ensaios. São Paulo: Hedra, 2007.

."Modern Science and Anarchism". In: BALDWIN, Roger (org.). Kropotkin's Revolutionary Panphlets. Nova York: Dover, 1970a.

. “Anarchist Communism”. In: BALDWIN, Roger (org.). Kropotkin's Revolutionary Panphlets. Nova York: Dover, $1970 b$.

. Palavras de um Revoltado. São Paulo: Imaginário/Ícone, 2005.

LEVAL, Gastón. Colectividades Libertarias em España. 2 vols. Buenos Aires: Proyección, 1972.

MALATESTA, Errico. “O Estado Socialista”. In: Anarquistas, Socialistas e Comunistas. São Paulo: Cortez, 1989.

. Ideologia Anarquista. Montevidéu: Recortes, 2008.

."Programa Anarquista”. In: Escritos Revolucionários. São Paulo: Imaginário, 2000.

MECHOSO, Juan C. Acción Directa Anarquista: una história de FAU. Tomos I, II, III e IV. Montevideu: Recortes, 2011, 2005, 2006, 2009.

MINTZ, Frank. La Autogestión en la España Revolucionaria. Madri: La Piqueta, 1977.

PAZ, Abel. O Povo em Armas. 2 vols. Lisboa: Assírio e Alvim, s/d.

PEIRATS, José. Los Anarquistas en la Crisis Política Española (1869-1939). Buenos Aires, Anarres, 2006.

PROUDHON, Pierre-Joseph. A Nova Sociedade. Porto: Rés, s/d.

RECLUS, Élisée. A Evolução, a Revolução e o Ideal Anarquista. São Paulo: Imaginário, 2002.

RICHARDS, Vernon (org.) Malatesta: pensamiento y acción revolucionários. Buenos Aires: Anarres, 2007.

ROSSINERI, Patrick. "La Quimera del Poder Popular". In: Anarquismo y Poder Popular: teoría y práctica suramericana. Bogotá: Gato Negro, 2011.

Em Debat: Rev. Dig., ISSNe 1980-3532, Florianópolis, n. 8, p. 69-89, jul-dez, 2012. 
RUGAI, Ricardo R. O Anarquismo Organizado: as concepções práticas da Federação Anarquista Uruguaia (1952-1976). Campinas, UNICAMP (mestrado em História), 2003.

SAMIS, Alexandre. "Introdução". In: MAGÓN, Ricardo F. A Revolução Mexicana. São Paulo: Imaginário, 2003.

SCHMIDT, Michael. Anarquismo Búlgaro em Armas: a linha de massas anarco-comunista. Vol. I. São Paulo: Faísca, 2009.

SCHMIDT, Michael; VAN DER WALT, Lucien. Black Flame: the revolutionary class politics of anarchism and syndicalism. Oakland: AK Press, 2009.

SCHUJMAN, Héctor. La Revolución Desconocida: Ukrania 1917-1921, la gesta makhnovista. Mostoles: Nossa y Jara, 2000.

SKIRDA, Alexandre. Les Anarchistes Russes, les Sovietes et la Révolution de 1917. Paris: Éditions de Paris, 2000.

TRAGTENBERG, Mauricio. A Revolução Russa. São Paulo: Faísca, 2007.

TREJO, Rubén. Magonismo: utopia y revolución, 1910-1913. Cidade do México: Cultura Libre, 2005.

VOLIN. "Prólogo". In: ARSHINOV, Piotr. História do Movimento Macknovista: a insurreição dos camponeses na Ucrânia. Lisboa: Assírio e Alvim, 1976.

ZARCONE, Pier Francesco. Os Anarquistas na Revolução Mexicana. São Paulo: Faísca, 2006. 